\title{
ALGORITMO DE IDENTIFICAÇÃO DE FORMAS DA SUPERFÍCIE APLICADO AO RECONHECIMENTO PEDOLÓGICO NA BACIA HIDROGRÁFICA DO BAIXO TIBAGI - PARANÁ
}

\author{
SURFACE FORMS ALGORITHM IDENTIFICATION APPLIED TO PEDOLOGICAL RECOGNITION \\ IN THE LOWER TIBAGI WATERSHED BASIN - PARANÁ STATE
}

Estevão Conceição Gomes Junior ${ }^{\mathrm{A}}$

(iD) Mara de Andrade Marinho ${ }^{\mathrm{B}}$

(iD) Deise Fabiana Ely ${ }^{\mathrm{A}}$

\author{
${ }^{\text {A }}$ Universidade Estadual de Londrina (UEL), Londrina, PR, Brasil \\ ${ }^{\text {B }}$ Universidade Estadual de Campinas (UNICAMP), Campinas, SP, Brasil
}

Recebido em: 01/03/2020 | Aprovado em: 14/05/2021～DOI: 10.12957/tamoios.2021.48788

Correspondência para: Estevão Conceição Gomes Junior (tevao.junior@gmail.com)

\begin{abstract}
Resumo
A Pedometria desponta na Ciência do Solo como uma nova maneira de observar quantitativamente a variabilidade espacial do solo e de seus atributos. Assim, como ferramenta auxiliar ao Mapeamento Digital de Solos, os algoritmos matemáticos inseridos em plataformas de Sistema de Informação Geográfica (SIG) podem realizar de forma automática uma análise preliminar dos elementos do meio físico (solo, relevo, litologia, vegetação) e assim complementar e otimizar o estudo do pesquisador. Desta forma, o presente estudo visou aplicar e validar o algoritmo matemático computacional TOPOSHAPE para delinear as formas da superfície em vertentes e predizer suas classes de solo associadas na Bacia Hidrográfica do Baixo Tibagi, localizado no centro-norte do estado do Paraná. Para o delineamento automatizado das formas da superfície foi criado o modelo digital de elevação (MDE) derivado da composição de imagens SRTM com resolução espacial de 30 metros (1 arco de segundo). Os resultados indicaram alta acurácia do algoritmo no reconhecimento das áreas de cumeeira associadas a solos mais profundos, como os Latossolos, as vertentes convexas associadas a solos mais rasos, como os Neossolos Regolíticos e as áreas de talvegues e planícies associadas a solos hidromórficos, como os Gleissolos. Por outro lado, o algoritmo apresentou baixa sensibilidade em encontrar padrões pedogenéticos quanto a subordens, o que exigiria uma escala de mapeamento em nível de detalhe ou ultradetalhe.
\end{abstract}

Palavras-chave: Pedometria; mapeamento digital de solos; pedologia; relação solo-relevo; Sistema de Informação Geográfica.

\begin{abstract}
Pedometrics emerges in Soil Science as a new way of observing the quantification of soil spatial variability and its attributes. Therefore, as an auxiliary tool for Digital Soil Mapping, the mathematical algorithms inserted in Geographic Information System (GIS) performs a preliminary analysis of the elements of the physical environment (soil, relief, lithology, vegetation), thus complementing and optimizing the researcher's study. The present study aimed to validate the computational algorithm TOPOSHAPE to delineate the slope surface forms associated with the soil classes in the Lower Tibagi Watershed Basin, located in the north-central part of the state of Paraná. For the automated design of the surface forms, a digital elevation model (DEM) derived from the SRTM images with a spatial resolution of 30 meters (1 arc a second) was created. The results indicate the high accuracy of the algorithm in recognition of the ridge areas associated with the deeper soils, such as the Oxisols, the convex slopes associated with shallower soils, such as the Entisols Orthents and lowest areas associated to talweg and floodplain to hydromorphic soils, such as the Entisols Aquents and Alfisols Aqualfs. On the other hand, the algorithm showed low sensitivity in finding pedogenetic patterns as to soil suborders, which would require a mapping scale at the level of detail or ultra-detail.
\end{abstract}

Keywords: Pedometrics; digital soil mapping; pedology; soil-relief relationship; Geographic Information System. 


\section{INTRODUÇ̃̃O}

O estudo quantitativo dos elementos da paisagem tornou-se ainda mais significativo com o aprimoramento das geotecnologias e seus subprodutos, como o Geoprocessamento e o Sensoriamento Remoto e Proximal (McBratney et al. 2003; Ten Caten, 2011). Nesta direção, cresce na Ciência do Solo a Pedometria, ramo responsável pela aplicação de métodos matemáticos e estatísticos para o estudo da gênese e distribuição dos solos e de seus atributos.

Inserido no contexto conceitual da Pedometria, o Mapeamento Digital de Solos (MDS) se mostra com um ramo promissor para a ciência geográfica, tendo em vista o arcabouço teórico-metodológico eminente na formação do geógrafo contemporâneo: o conhecimento dos Sistemas de Informação Geográficas (SIG's), da cartografia digital e da observação/interpretação dos fenômenos e elementos do meio físico. Assim, segundo Lagacherie e McBratney (2007), o MDS visa à criação de sistemas espaciais de informação de solos empregando modelos numéricos, correlacionando o conhecimento dos solos com a de outras variáveis ambientais.

Dentre as variáveis ambientais mais utilizadas no MDS destacam-se as variáveis topográficas ou morfométricas derivadas do relevo e relacionadas com medidas de curvatura, declividade e ângulo de orientação da vertente, de grande significância para os processos pedogenéticos.

A relação entre relevo (fator pedogenético) e desenvolvimento do solo ainda apresentam expressiva relevância internacional. Trabalhos pioneiros incluem os de Davis (1899), Milne (1935), Penck (1953), Ruhe (1956) e King (1963). Trabalhos mais recentes, já no âmbito da Pedometria, incluem os de Ten Caten (2011), Giasson (2011), Silva (2012), Hofig (2014), Gomes Júnior (2017), entre outros.

Já descrita na equação $\underline{\text { Clorpt }}(\mathrm{cl}=$ clima, $\mathrm{o}=$ organismos, $\mathrm{r}=\mathrm{relevo}, \mathrm{p}=$ material de origem, $\mathrm{t}=$ tempo) (Jenny, 1941), transformada em $\underline{\text { Scorpan }}$ (s=informações prévias do solo, $\mathrm{c}=$ clima, $\mathrm{o}=$ organismos, $\mathrm{r}=$ relevo, $\mathrm{p}=$ material de origem, $\mathrm{a}=$ tempo, $\mathrm{n}=$ posição espacial) para significar o estudo quantitativo dos solos (McBratney et al.,2003), a relação entre solo e relevo tem como objetivo identificar fortes correlações entre a gênese e distribuição dos solos associadas à condição do relevo na paisagem.

Algoritmos morfométricos computacionais surgem como uma metodologia de apoio ao estudo da variabilidade espacial dos solos, sendo possível verificar diferentes formas da superfície em vertentes associadas às classes de solo. Esta abordagem permite a predição de classes de solos ainda em escritório, ilustrando o cenário da realidade de campo.

O aproveitamento da informação de solos disponível nos levantamentos de solos já realizados possibilita a validação dos resultados gerados pelo algoritmo, permitindo o levantamento de dados quantitativos e mais detalhados acerca dos solos, promovendo redução de custos e do tempo para os trabalhos de campo.

O algoritmo matemático computacional TOPOSHAPE, inserido no SIG Idrisi ${ }^{\circledR}$, permite a identificação e separação das diferentes formas da superfície sobre uma vertente, indicando diferentes categorias, que levam em consideração a forma da superfície (concavidade, convexidade e retilíniaridade) e o fluxo de energia (deposição ou degradação). 
Desenvolvido por Pellegrini (1995) e adaptado por Gomes Júnior (2017), o TOPOSHAPE foi criado dentro do âmbito das discussões da Ciência do Solo como uma ferramenta de reconhecimento dos solos a partir de sua posição no relevo. O algoritmo utiliza como dado de entrada (input) um modelo digital de elevação do terreno (MDE). Com isso, cria-se uma classificação não-supervisionada que divide a vertente em onze possíveis categorias (topo, cumeeira, ponto sela, planície, talvegue, depressão fechada, vertente convexa, vertente em sela, vertente em declive, vertente côncava e inflexão da vertente), sendo uma décima segunda categoria criada quando o algoritmo encontra dificuldades de classificação.

A Bacia Hidrográfica do Baixo Tibagi tem seu alto curso na área de transição do Segundo para o Terceiro Planalto Paranaense, de condições pedogeomorfológicas distintas, devido à grande variabilidade de relevo e material de origem, indicando uma potencial área de estudo para reconhecimento de padrões espaciais quanto as formas da superfície em vertentes e solos associados.

Assim, o presente estudo visa aplicar e validar com base no mapa pedológico semidetalhado, de escala 1:250.000 já publicado para a área de estudo, o algoritmo matemático computacional TOPOSHAPE, verificando a acurácia da correlação pedogeomorfológica das formas da superfície e os solos associados.

\section{MATERIAIS E MÉTODOS}

\section{Caracterização da área de estudo}

A Bacia Hidrográfica do Baixo Tibagi (BHBT) localiza-se entre as coordenadas

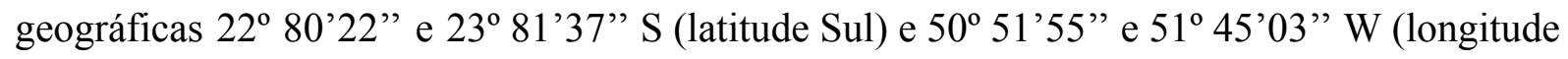
Oeste) (Figura 1). Esta bacia hidrográfica possui uma área total de $7.070 \mathrm{~km}^{2}$, contemplando 28 municípios, sendo Londrina, Cornélio Procópio, Apucarana e Arapongas de maior destaque econômico; a principal atividade econômica na BHBT é a agropecuária, com destaque para soja, milho, trigo e café. As pastagens ocupam apenas $14 \%$ da área $(\mathrm{CBH}$, 2009).

Figura 1 - Esquema de identificação da Bacia Hidrográfica do Baixo Tibagi. 


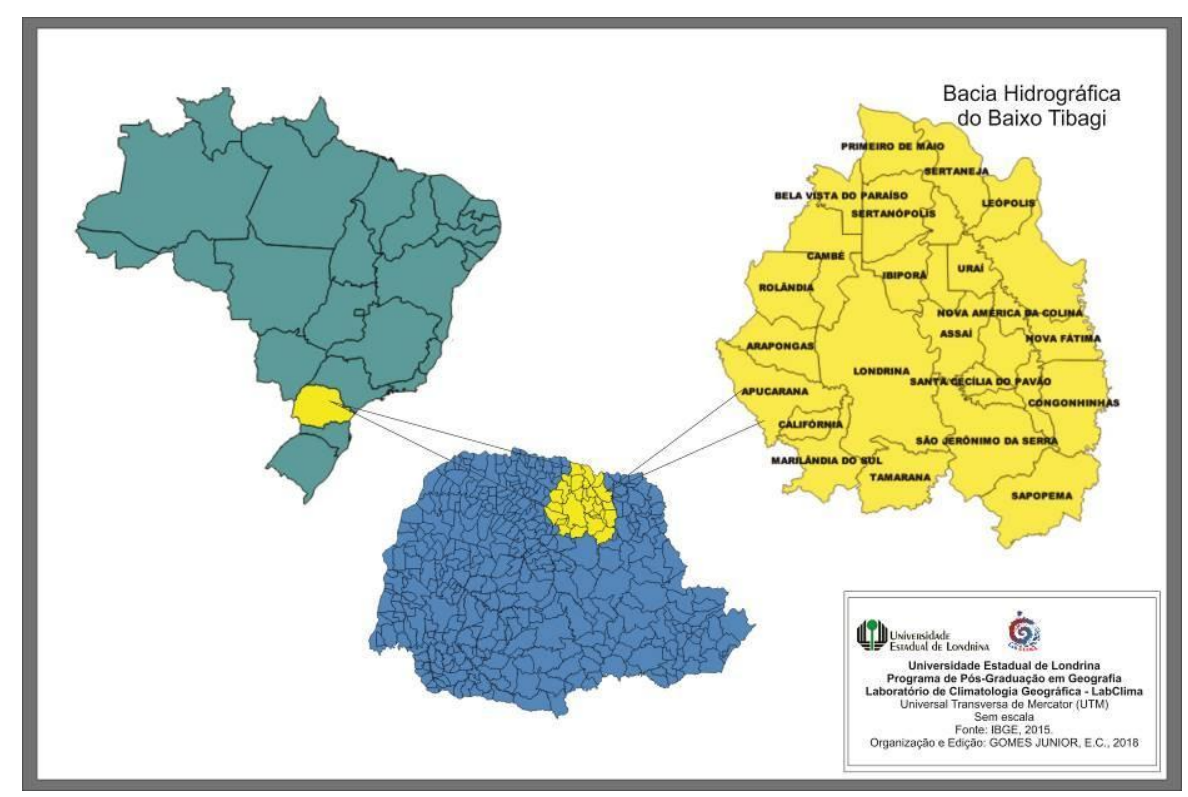

Fonte: Elaborado pelos autores.

Sob o ponto de vista geológico, a BHBT é composta predominantemente por rochas basálticas, localizando-se sob os domínios litoestratigráficos do Grupo São Bento, Formação Serra Geral, oriunda de um significativo conjunto de derrames de basaltos (Leinz ,1968), com arenitos de mesmas características aos dos pertencentes à Formação Botucatu (PINESE, 2002).

A hipsometria da BHBT indica maiores altitudes à sul, limite com o Segundo Planalto Paranaense, que decresce em altitude no sentido sul-norte, alcançando cotas inferiores a 325 metros na foz, no encontro com o Rio Paranapanema. (Figura 2):

Figura 2 - Hipsometria da BHBT. 


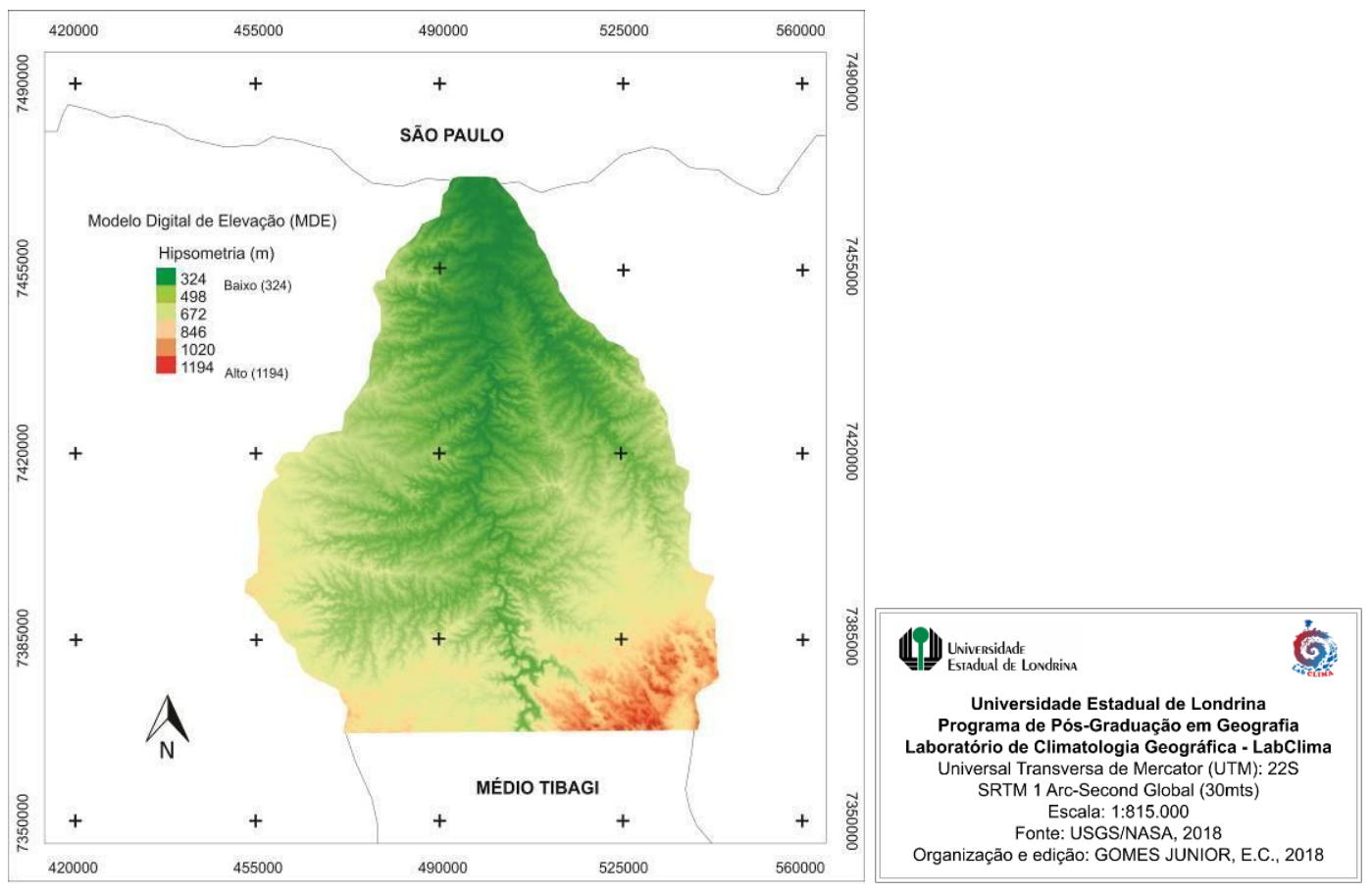

Fonte: Elaborado pelos autores.

\section{Procedimento metodológico}

\section{Algoritmo TOPOSHAPE: concepção teórico-metodológica}

O algoritmo TOPOSHAPE consiste na combinação suavizada da superfície terrestre com a determinação de classes funcionais, onde cada célula por meio da aplicação de um modelo matemático (vizinho mais próximo) é possível mapear a superfície e obter acurácia de 90\% na classificação (HERRINGTON e PELLEGRINI, 2000).

Trata-se de um modelo desenvolvido a partir do ajuste polinomial de segunda-ordem, baseado no método de Jacobi (STRONG, 2007), em que há uma janela móvel de 3x3 (contendo nove pontos no plano quadrático com grid, de 1 a 9) que se desloca ao longo do MDE para calcular os valores das variáveis morfométricas para todos os pixels do plano quadrático do MDE, exceto para as linhas e colunas do pixel. Assim, a partir do modelo polinomial, cada célula resulta da característica mais importante ocorrida dentro do pixel.

Para o ajuste das formas da superfície em uma janela móvel de 3x3 foi utilizada a equação quártica parcial (ZEVENBERGEN e THORNE, 1987) apresentada a seguir:

$$
Z=f(x, y)=A x^{2} y^{2}+B x^{2} y+C x y^{2}+D x^{2}+E y^{2}+F x y+G x+H y+1
$$

Onde: 


$$
A=\left[\frac{\left(\frac{\{z 1+z 3+z 7+z 9\}}{4}\right)-\left(\frac{\{z 2+z 4=z 6+z 8\}}{2}\right)+z 5}{L^{4}}\right]
$$

$B=\left[\frac{\left(\frac{\{z 1+z 3+z 7+z 9\}}{4}\right)+\left(\frac{\{z 2-z 8\}}{2}\right)}{L^{3}}\right]$

$C=\left[\frac{\left(\frac{\{z 1+z 3+z 7+z 9\}}{4}\right)+\left(\frac{\{z 4-z 6\}}{2}\right)}{L^{3}}\right]$

$D=\left[\frac{\left(\frac{\{z 4+z 6\}}{2}\right)-z 5}{L^{2}}\right]$

$E=\left[\frac{\left(\frac{\{z 2+z 8\}}{2}\right)-z 5}{L^{2}}\right]$

$F=\frac{-z 1+z 3+z 7-z 9}{4 L^{2}}$

$G=\frac{-z 4+z 6}{2 L}$

$H=\frac{z 2-z 8}{2 L}$ 


$$
I=z 5
$$

$(E q$.

2)

Esse polinômio fornece um ajuste para os pontos de elevação da superfície na janela móvel de 3x3, desde que não haja descontinuidades (falésias ou escarpas) (PELLEGRINI, 1995). As equações para determinar inclinação, aspecto (orientação) e as duas medidas de curvatura podem ser encontradas em Pellegrini (1995). A derivada direcional para a célula central da janela é dada por Pellegrini (1995) como:

$$
\frac{d^{2} Z}{d^{2} S}=2 D \cos ^{2} \theta+2 E \operatorname{sen}^{2} \theta+2 F \operatorname{sen} \theta \cos \theta
$$

3)

Do ponto de vista da análise de superfície, essa derivada fornece todas as informações necessárias para classificar corretamente a forma da janela. Assume-se que as mudanças significativas na forma da superfície são mais facilmente identificadas quando se avalia a segunda derivada em locais onde a curvatura da superfície é máxima.

Resolver a derivada acima para seus valores extremos requer a determinação do ângulo que a maximiza (PELLEGRINI, 1995; HERRINGTON E PELLEGRINI, 2000). Sendo assim, a equação 03 pode ser transformada em:

$$
f^{\pi} 5=[\cos \theta \operatorname{sen} \theta]\left[\begin{array}{cc}
2 D & F \\
F & 2 E
\end{array}\right]\left[\begin{array}{cc}
\cos \theta & \cos \theta \\
\operatorname{sen} \theta & \operatorname{sen} \theta
\end{array}\right]=x^{t} H x
$$

4)

Onde $\mathrm{x}^{\mathrm{t}} \mathrm{e}$ a transposta de $\mathrm{x}$. Essa forma quadrática da derivada fornece uma maneira de isolar os componentes individuais da segunda derivada (Eq. 3). A matriz simétrica $2 \times 2 \mathrm{H}$ é um arquivo de matriz de um classificador avançado que contém toda a informação de curvatura da função (STRANG, 1976; PELLEGRINI, 1995). As raízes dessas equações são as direções da curvatura máxima e mínima da superfície.

\section{Procedimentos técnico-operacionais}

Seguiu-se o seguinte delineamento experimental: 
- Aquisição de imagens Shuttle Radar Topography Mission (SRTM) com 1 Arco Segundo Global, com resolução espacial de 30 metros para criação do MDE;

- Montagem do mosaico das cenas SRTM que abrangem a área de estudo no software QGIS;

- Exportação do MDE para o software IDRISI;

- Exportação do Mapa Pedológico do estado do Paraná para o software IDRISI;

- Vetorização das unidades de mapeamento do Mapa Pedológico do estado do Paraná para aquisição da área $\left(\mathrm{km}^{2}\right)$ e \% de ocorrência na BHBT;

- Rodagem da rotina do algoritmo TOPOSHAPE no IDRISI;

- Interpolação do resultado do TOPOSHAPE com as unidades de mapeamento;

- Validação das formas da superfície em vertentes encontradas com as classes de solo associadas.

\section{Validação do algoritmo}

A validação do algoritmo foi obtida através da análise da tabulação cruzada comparativa através de duas variáveis (formas da superfície e classes de solo), baseado na classificação fuzzy (BURROUGH, 1989). Assim, com o objetivo de identificar a acurácia do algoritmo foram extraídos do output: a área $\mathrm{em}^{\mathrm{km}}{ }^{2}$ das formas da superfície em cada unidade de mapeamento de solo, observando se há correlação pedogeomorfológica entre as formas da superfície e os solos associados.

\section{RESULTADOS}

Foram identificadas na BHBT cinco subordens pedológicas - Nitossolos Vermelhos (NV), Latossolos Vermelhos (LV), Neossolos Regolíticos (RR), Argissolos Vermelho-Amarelos (PVA) e Gleissolos Háplicos (GX), a partir do mapeamento pedológico do estado do Paraná (Embrapa, 2008), escala 1:250.000 (Figura 3).

Figura 3 - Mapa pedológico da BHBT.

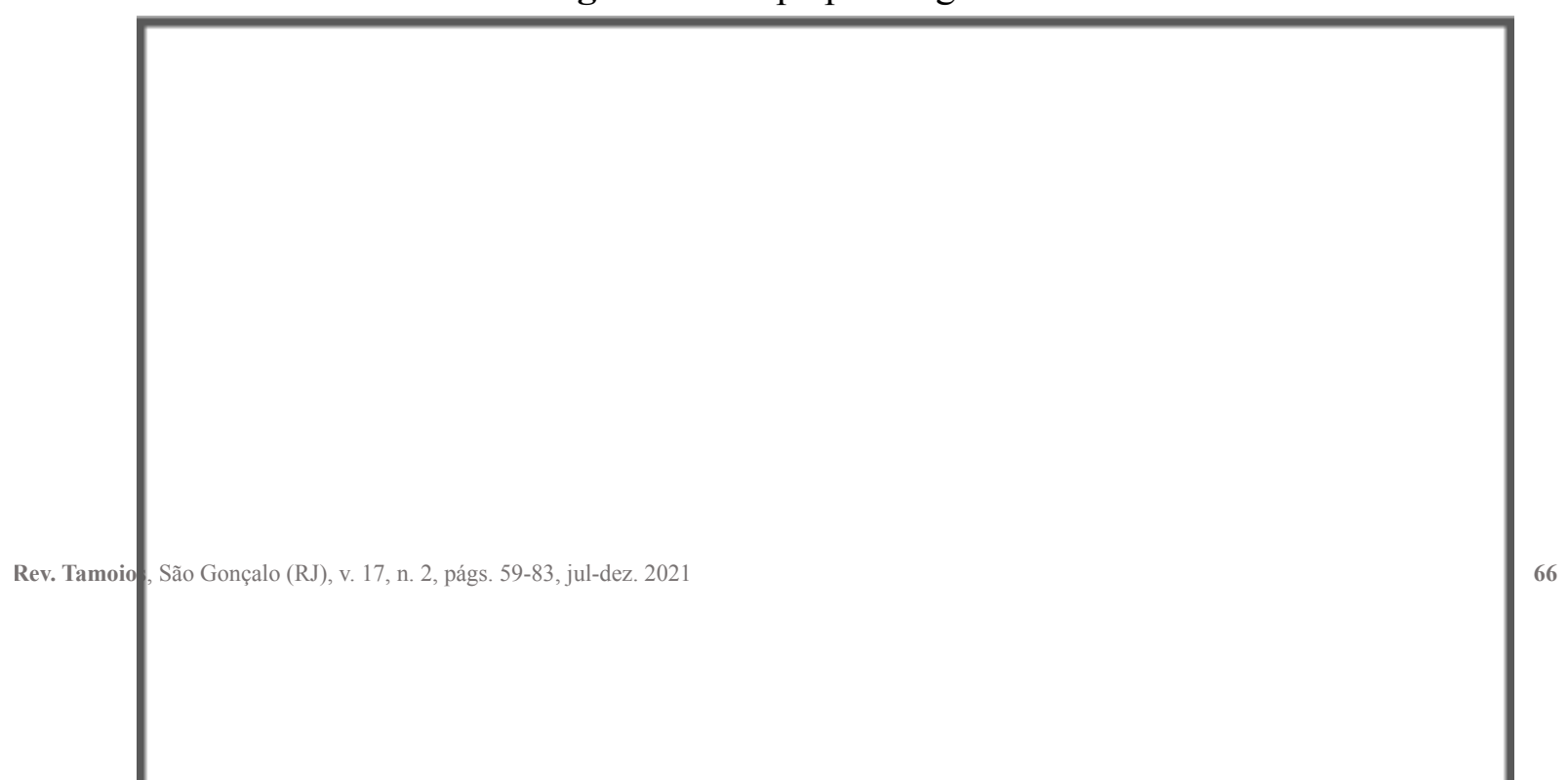




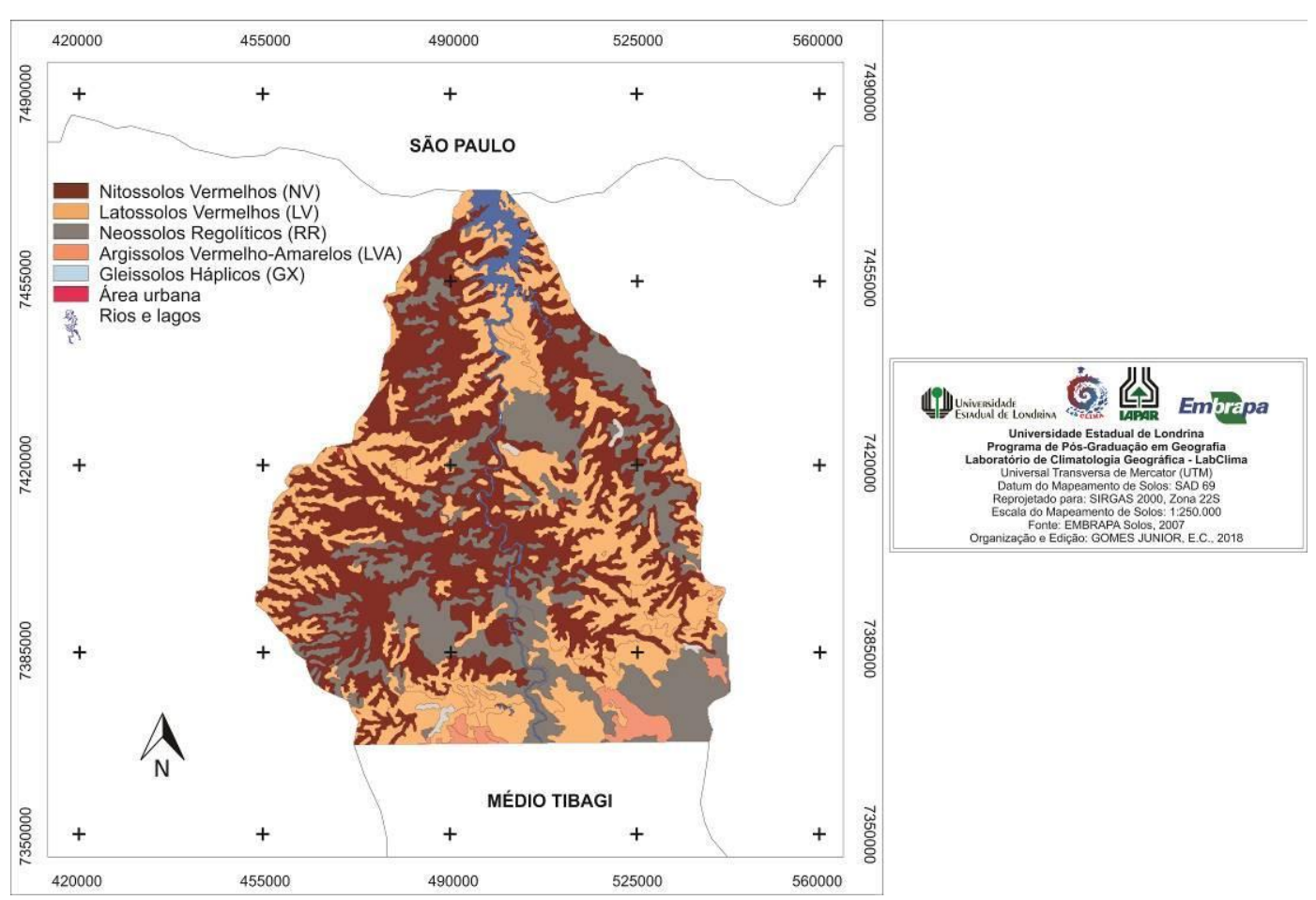

Fonte: Elaborado pelos autores.

Destacam-se na área os Nitossolos Vermelhos e os Latossolos Vermelhos, recorrentes em mais de $70 \%$ da área (Tabela 1). A ordem dos Nitossolos ocorre em apenas $1,13 \%$ do território nacional (Embrapa, 2006) e em 15,18\% no estado do Paraná (EMBRAPA, 2007). $\mathrm{Na}$ área de estudo os Nitossolos Vermelhos ocorrem em $2.902 \mathrm{~km}^{2}$, cerca de $41 \%$ da área total da BHBT.

Tabela 1. Subordens pedológicas identificadas na BHBT.

\begin{tabular}{c|c|c}
\hline Subordens & Área $\left.\mathbf{( k m}^{\mathbf{2}}\right)$ & Ocorrência $\mathbf{( \% )}$ \\
\hline Nitossolos Vermelhos (NV) & 2902,5 & 41,05 \\
\hline Latossolos Vermelhos (LV) & 2261,7 & 31,99 \\
\hline Neossolos Regolíticos (RR) & 1562,2 & 22,09 \\
\hline Argissolos Vermelho-Amarelos (PVA) & 126,2 & 1,78 \\
\hline Gleissolos Háplicos (GX) & 30,6 & 0,43 \\
\hline Área urbana & 5,5 & 0,08 \\
\hline Rios e lagos & 182 & 2,57 \\
\hline TOTAL & 7070,7 & 100,00
\end{tabular}

Fonte: Elaborado pelos autores.

Ao analisar a resposta do TOPOSHAPE as formas da superfície na BHBT observam-se a ocorrência das onze possíveis formas da superfície (Figura 4), além de 0,86\% de áreas não classificadas pelo algoritmo. 
Figura 4 - Formas da superfície pelo algoritmo TOPOSHAPE.

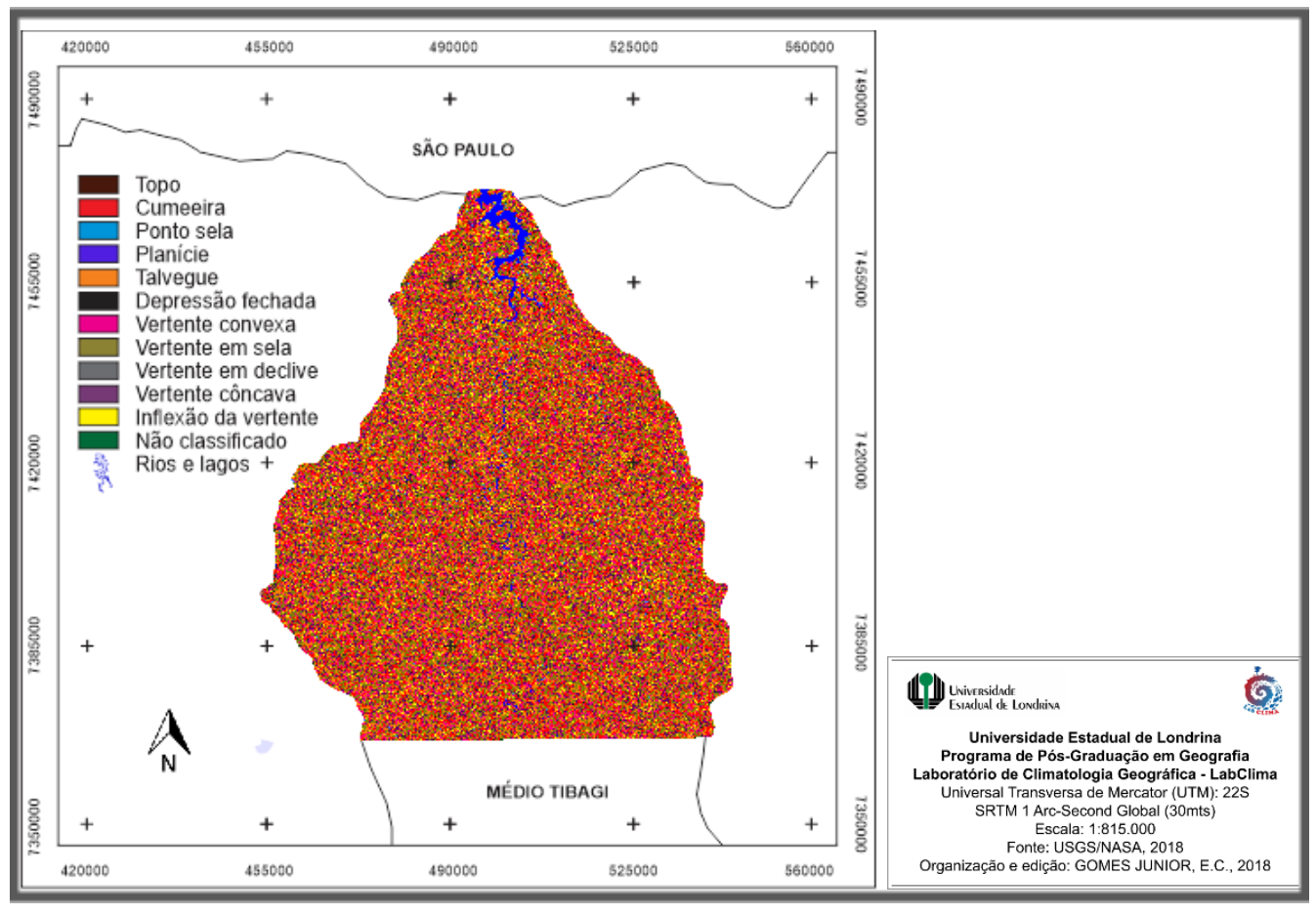

Fonte: Elaborado pelos autores.

Predominam na BHBT as vertentes em sela e as regiões de cumeeira (Tabela 2). As vertentes em sela sinalizam que há curvatura positiva em uma direção e negativa em sua ortogonal. Já as regiões de cumeeira indicam um conjunto de células que ocorrem quando as células são mais altas que as células circunvizinhas, também conhecida como linha de cumeada (PELLEGRINI, 1995; OLIVEIRA, 2009; GOMES JUNIOR, 2017).

Tabela 2 - Formas da superfície das vertentes identificadas pelo algoritmo TOPOSHAPE na BHBT.

\begin{tabular}{c|c|c}
\hline Formas da superfície & Área $\left.\mathbf{( k m}^{\mathbf{2}}\right)$ & Ocorrência (\%) \\
\hline Topo & 419,79 & 6,10 \\
\hline Cumeeira & 1262,5 & 18,34 \\
\hline Ponto sela & 121,66 & 1,77 \\
\hline Planície & 11,12 & 0,16 \\
\hline Talvegue & 970,5 & 14,10 \\
\hline Depressão fechada & 4,69 & 0,07 \\
\hline Vertente convexa & 1037,7 & 15,08 \\
\hline Vertente em sela & 1435,2 & 20,85 \\
\hline Vertente em declive & 358 & 5,20 \\
\hline Vertente côncava & 770 & 11,19 \\
\hline Inflexão da vertente & 432,9 & 6,29 \\
\hline Não classificado & 59,4 & 0,86
\end{tabular}




\begin{tabular}{c|c|c}
\hline TOTAL & 6883,46 & 100,00 \\
\hline
\end{tabular}

Fonte: Elaborado pelos autores.

Ao observar as subordens de solo da BHBT individualmente, verifica-se concordância das formas da superfície com os solos associados, tomando como base a concepção teórica (base e critério) do processo pedogenético das ordens. Assim, os Nitossolos Vermelhos caracterizados por possuírem a fração argila de baixa capacidade catiônica, serem profundos e porosos, além da boa drenagem ocorreram associados as vertentes em sela, regiões de talvegue e áreas de cumeeira (Figura 5).

Figura 5 - Formas da superfície associadas aos Nitossolos Vermelhos.

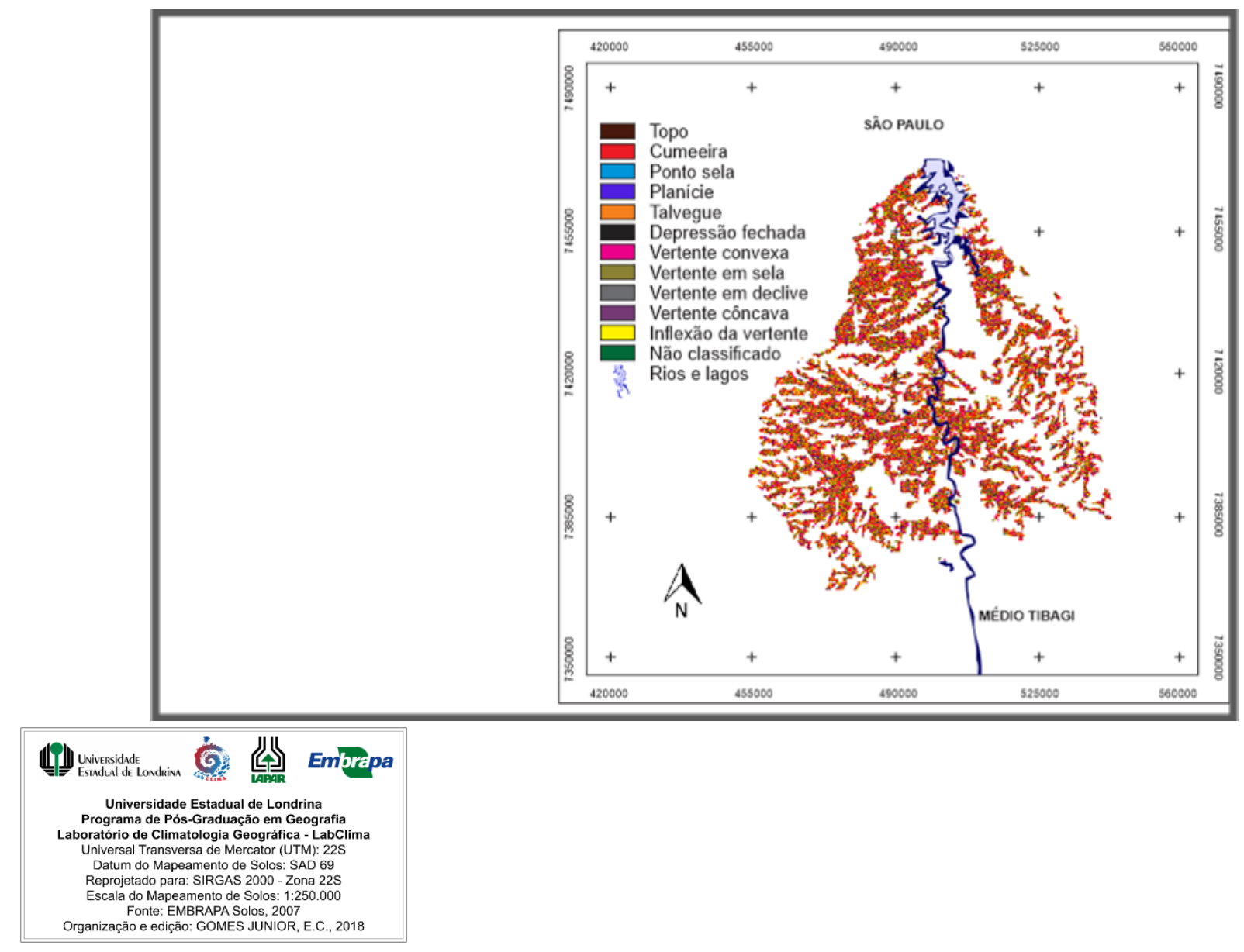

Fonte: Elaborado pelos autores.

A variação do posicionamento dos Nitossolos Vermelhos nas vertentes pode ser explicada, como descrito por Gôngora e Nobrega (2002), pela estabilidade das estruturas em blocos angulares ou subangulares, que diminuem o impacto das forças causadoras da erosão. Ao verificar as unidades de mapeamento descritas na BHBT, os Nitossolos Vermelhos Eutroférricos (NVef2, NVef3 e NVef8) ocorrem em 96\% da área, contra apenas 4\% dos Nitossolos Vermelhos Distroférricos (NVdf3) (Tabela 3). 
Tabela 3. Unidades de mapeamento (Nitossolos) e área de ocorrência (\%) na BHBT.

\begin{tabular}{c|c|c}
\hline $\begin{array}{c}\text { Unidades de } \\
\text { mapeamento }\end{array}$ & Descrição & $\begin{array}{c}\text { Ocorrência } \\
\text { na BHBT (\%) }\end{array}$ \\
\hline NVdf3 & Nitossolo Vermelho Distroférrico úmbrico & $4 \%$ \\
\hline NVef2 & $\begin{array}{c}\text { Nitossolo Vermelho Eutroférrico típico, relevo } \\
\text { ondulado }\end{array}$ & $73 \%$ \\
\hline NVef3 & $\begin{array}{c}\text { Nitossolo Vermelho Eutroférrico típico, relevo } \\
\text { suave ondulado }\end{array}$ & $13 \%$ \\
\hline NVef8 & Nitossolo Vermelho Eutroférrico latossólico & $10 \%$ \\
\hline
\end{tabular}

Fonte: Elaborado pelos autores.

Tal superioridade dos Eutroférricos ( $3^{\circ}$ nível categórico) pode ser um indicador da predominância das formas da superfície encontradas em pontos mais baixos das vertentes, como os talvegues (Tabela 4) e nas vertentes em sela (curvatura positiva em uma direção e negativa em sua ortogonal). Isso porque as porções de menor declividade tendem a apresentar maior estabilidade morfogênica, potencializando a formação do solo, herdando mais intensamente os elementos químicos do material litológico, no caso as rochas basálticas do Grupo São Bento, Formação Serra Geral.

Tabela 4. Formas da superfície das vertentes identificadas pelo algoritmo TOPOSHAPE nos Nitossolos Vermelhos.

\begin{tabular}{c|c|c}
\hline Segmentos de vertente & Área $\left(\mathbf{k m}^{\mathbf{2}}\right)$ & Ocorrência $\mathbf{( \% )}$ \\
\hline Topo & 1,7 & 0,06 \\
\hline Cumeeira & 399,4 & 13,76 \\
\hline Ponto sela & 101 & 3,48 \\
\hline Planície & 2,76 & 0,10 \\
\hline Talvegue & 564,8 & 19,46 \\
\hline Depressão fechada & 1,99 & 0,07 \\
\hline Vertente convexa & 249,6 & 8,60 \\
\hline Vertente em sela & 996,6 & 34,34 \\
\hline Vertente em declive & 22,2 & 0,76 \\
\hline Vertente côncava & 298,3 & 10,28 \\
\hline Inflexão da vertente & 239,2 & 8,24 \\
\hline Não classificado & 25 & 0,86 \\
\hline TOTAL & 2902,55 & 100,00 \\
\hline
\end{tabular}

Fonte: Elaborado pelos autores.

Os Latossolos Vermelhos, segunda subordem com maior área de ocorrência na BHBT (Figura 6) são muito profundos na sequência de horizontes $A, B, C$, com espessura $A+B$ 
normalmente superior a 3 metros, muito porosos, permeáveis, bem drenados e com baixo gradiente textural (EMBRAPA, 2007; EMBRAPA, 2013).

Figura 6 - Formas da superfície associadas aos Latossolos Vermelhos.

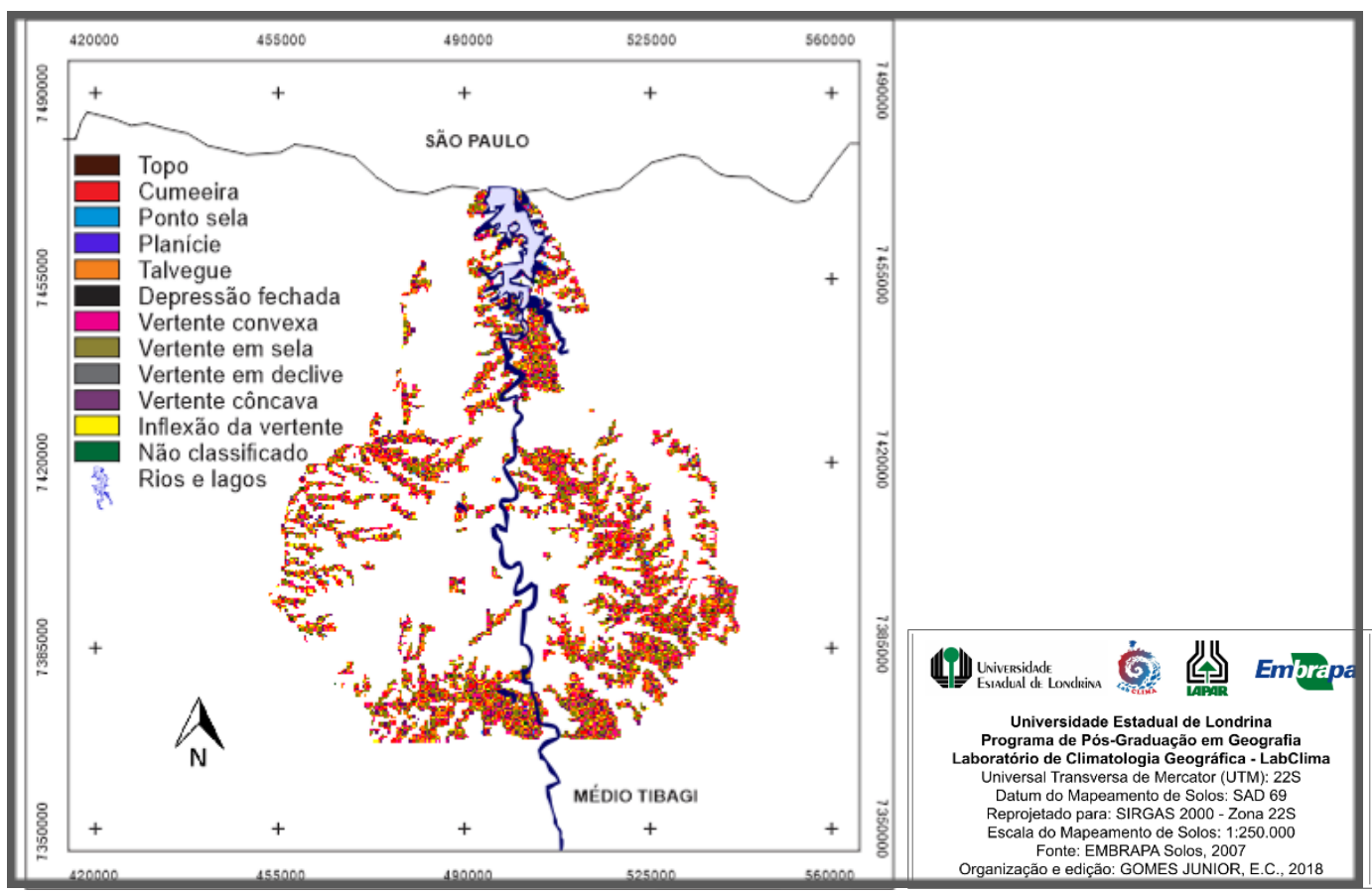

Fonte: Elaborado pelos autores.

A classificação das formas da superfície pelo TOPOSHAPE indicou os Latossolos Vermelhos associados às regiões de cumeeira (26,9\%) e topo (17,5\%) (Tabela 5). Os Latossolos ocupam, primariamente, áreas com relevos planos a suave-ondulados, localizados em posições de topo até o terço médio das vertentes, em áreas típicas de derrames basálticos (SOUZA e LOBATO, 2008).

Tabela 5 - Formas da superfície das vertentes identificadas pelo algoritmo TOPOSHAPE nos Latossolos Vermelhos.

\begin{tabular}{c|c|c}
\hline Segmentos de vertente & Área $\left.\mathbf{( k m}^{\mathbf{2}}\right)$ & Ocorrência (\%) \\
\hline Topo & 397,5 & 17,57 \\
\hline Cumeeira & 610 & 26,97 \\
\hline Ponto sela & 16 & 0,71 \\
\hline Planície & 3,77 & 0,17 \\
\hline Talvegue & 230 & 10,17 \\
\hline Depressão fechada & 2,1 & 0,09 \\
\hline Vertente convexa & 320,9 & 14,19 \\
\hline Vertente em sela & 202,4 & 8,95 \\
\hline Vertente em declive & 30,1 & 1,33 \\
\hline
\end{tabular}




\begin{tabular}{c|l|l}
\hline Vertente côncava & 293,7 & 12,99 \\
\hline Inflexão da vertente & 132,4 & 5,85 \\
\hline Continua Tabela 5. & \\
\hline Não classificado & 22,9 & 1,01 \\
\hline TOTAL & 2261,77 & 100,00 \\
\hline
\end{tabular}

Fonte: Elaborado pelos autores.

As unidades de mapeamento que possuem a ordem dos Latossolos como componente principal na BHBT indicaram o predomínio, em $\mathrm{km}^{2}$, do caráter eutroférrico (Tabela 6). $\mathrm{O}$ caráter eutroférrico indica saturação por bases maior que 50\% combinado a teores de óxidos de ferro entre 180 e $<360 \mathrm{~g} . \mathrm{kg}^{-1}$, sendo um caráter para separar algumas classes no $2^{\circ}$ nível categórico para as ordens dos Argissolos e Latossolos (IBGE, 2007).

Tabela 6 - Unidades de mapeamento (Latossolos) e área de ocorrência (\%) na BHBT.

\begin{tabular}{c|c|c}
\hline $\begin{array}{c}\text { Unidades de } \\
\text { mapeamento }\end{array}$ & Descrição & $\begin{array}{c}\text { Ocorrência na } \\
\text { BHBT (\%) }\end{array}$ \\
\hline LVd9 & Latossolo Vermelho Distrófico típico, textura \\
argilosa & $4 \%$ \\
\hline LVd19 & Latossolo Vermelho Distrófico típico, textura média & $0,5 \%$ \\
\hline LVdf4 & $\begin{array}{c}\text { Latossolo Vermelho Distroférrico típico A } \\
\text { moderado, álico, relevo suave ondulado }\end{array}$ & $11 \%$ \\
\hline LVdf6 & $\begin{array}{c}\text { Latossolo Vermelho Distroférrico típico A } \\
\text { moderado, álico, relevo plano }\end{array}$ & $5 \%$ \\
\hline LVdf11 & $\begin{array}{c}\text { Associação de Latossolo Vermelho Distroférrico } \\
\text { típico + Nitossolo Vermelho Distroférrico típico }\end{array}$ & $12 \%$ \\
\hline LVdf14 & $\begin{array}{c}\text { Latossolo Vermelho Distroférrico típico, A } \\
\text { moderado }\end{array}$ & $9 \%$ \\
\hline LVe1 & Latossolo Vermelho Eutrófico típico & $1,5 \%$ \\
\hline LVef2 & $\begin{array}{c}\text { Associação de Latossolo Vermelho Eutroférrico } \\
\text { típico + Nitossolo Vermelho Eutroférrico típico }\end{array}$ & $23 \%$ \\
\hline LVef3 & Latossolo Vermelho Eutroférrico típico & $34 \%$ \\
\hline
\end{tabular}

Fonte: Elaborado pelos autores.

A subordem dos Neossolos Regolíticos ocorre em 22\% na BHBT (Figura 7), tendo a unidade de mapeamento RRe10 como preponderante na área $(99,2 \%)$. A unidade de mapeamento RRe10 indica associação de Neossolo Regolítico Eutrófico chernossólico substrato rochas eruptivas básicas + Chernossolo Argilúvico Férrico + Nitossolo Vermelho Eutroférrico, ambos localizados em relevo suave ondulado a ondulado.

Os Neossolos Regolíticos na BHBT se localizam de forma homogênea, com pontos concentrados em São Jerônimo da Serra, Londrina e Rancho Alegre, em áreas de cultivo de milho, soja, culturas perenes e pastagem. Predominaram na área de ocorrência dos Neossolos Regolíticos as vertentes convexas $(28,6 \%)$ e as vertentes em declive (19,5\%) (Tabela 7). 
Figura 7 - Formas da superfície associadas aos Neossolos Regolíticos.

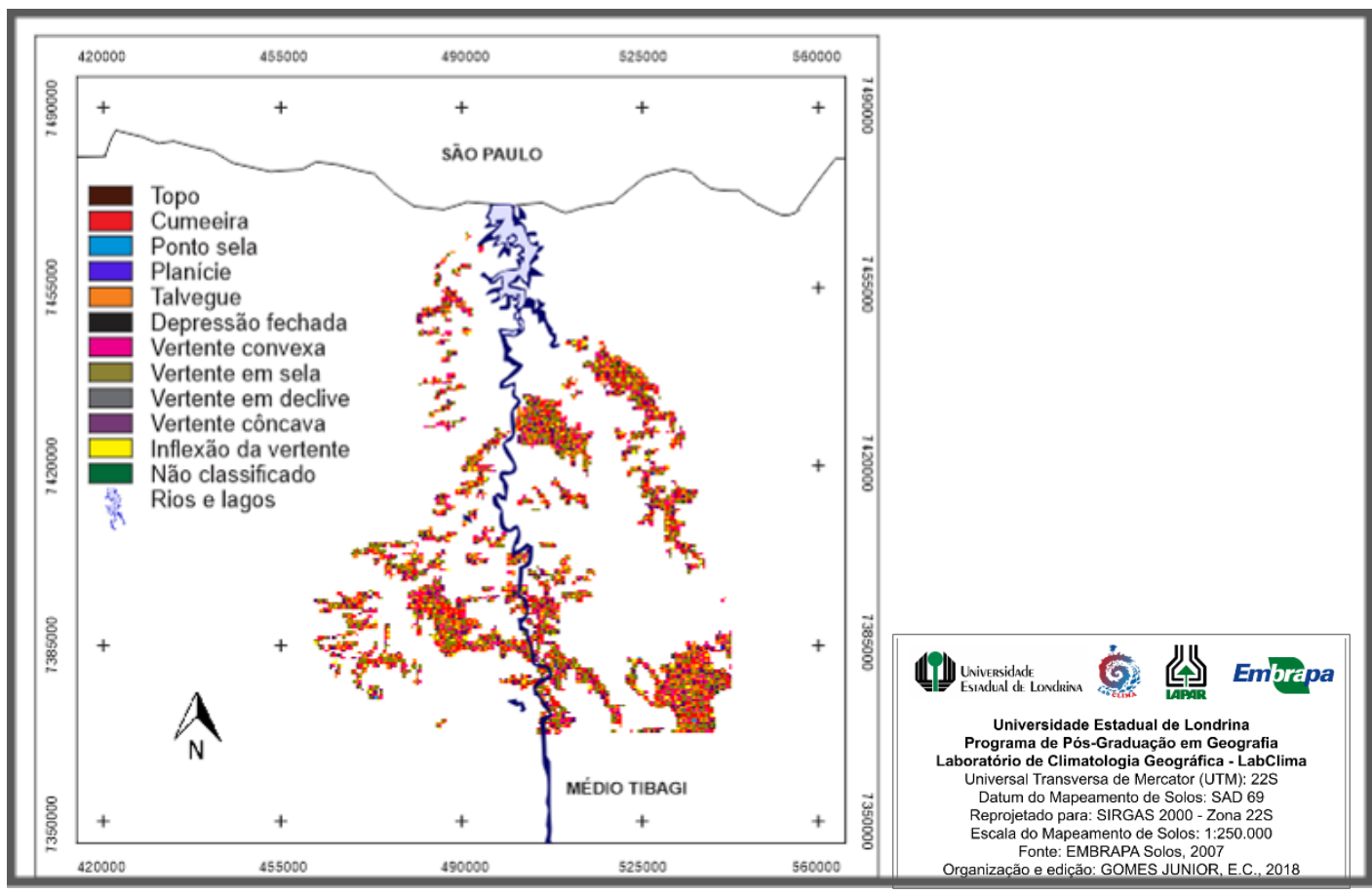

Fonte: Elaborado pelos autores.

Tabela 7 - Formas da superfície das vertentes identificadas pelo algoritmo TOPOSHAPE nos Neossolos Regolíticos.

\begin{tabular}{c|c|c}
\hline Segmentos de vertente & Área $\left.\mathbf{( k m}^{\mathbf{2}}\right)$ & Ocorrência $\mathbf{( \% )}$ \\
\hline Topo & 0,49 & 0,03 \\
\hline Cumeeira & 218,2 & 13,97 \\
\hline Ponto sela & 3,16 & 0,20 \\
\hline Planície & 0,43 & 0,03 \\
\hline Talvegue & 151,1 & 9,67 \\
\hline Depressão fechada & 0,6 & 0,04 \\
\hline Vertente convexa & 447,3 & 28,63 \\
\hline Vertente em sela & 216,6 & 13,86 \\
\hline Vertente em declive & 305 & 19,52 \\
\hline Vertente côncava & 154 & 9,86 \\
\hline Inflexão da vertente & 55,2 & 3,53 \\
\hline
\end{tabular}




\begin{tabular}{c|c|c}
\hline Não classificado & 10,2 & 0,65 \\
\hline TOTAL & 1562,28 & 100,00 \\
\hline
\end{tabular}

Fonte: Elaborado pelos autores.

Tal classificação indica a alta acurácia do algoritmo em identificar feições em vertentes com instabilidade pedogenética, ou seja, vertentes que apresentam movimentação de massas, dificultando o desenvolvimento dos horizontes superficiais do solo. Isso porque os Neossolos Regolíticos apresentam contato a partir de $50 \mathrm{~cm}$, caracterizados por solos pouco evoluídos, com horizonte B ausente ou com desenvolvimento insuficiente, gerando solos rasos. A subordem dos Argissolos Vermelho-Amarelos ocorreram associados às altas altitudes da porção sul do Rio Tibagi na BHBT, compondo 1,7\% dos solos da bacia (Figura 8).

Figura 8 - Formas da superfície associadas aos Argissolos Vermelho-Amarelos.

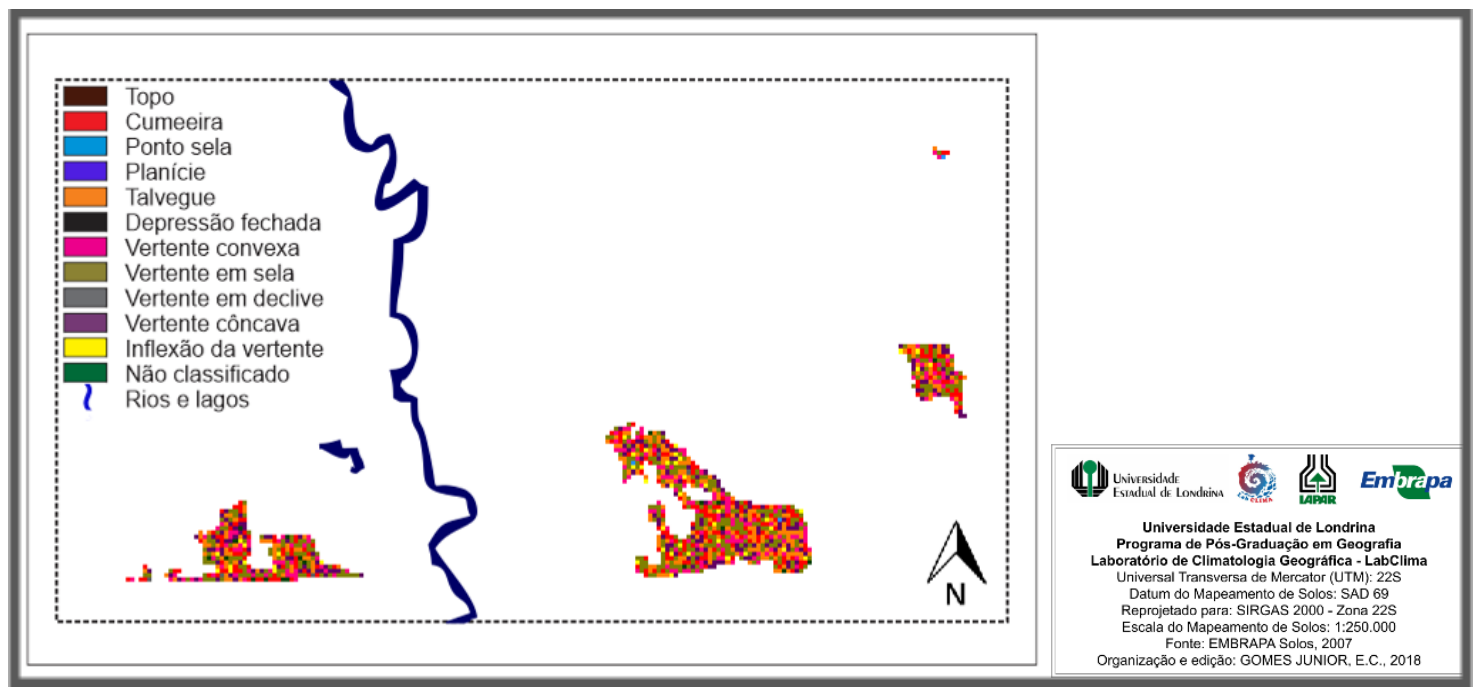

Fonte: Elaborado pelos autores.

As formas da superfície mais associadas aos Argissolos Vermelho-Amarelos na BHBT foram áreas de topo $(15,9 \%)$ e cumeeira $(26,9 \%)$ (Tabela 8). Esta subordem ocorre na BHBT como componente principal, sem associações, sendo descrita até o $4^{\circ}$ nível categórico como Argissolo Vermelho-Amarelo Distrófico úmbrico, textura média/argilosa, em relevo ondulado (PVAd2). 
Tabela 8. Formas da superfície das vertentes identificadas pelo algoritmo TOPOSHAPE nos Argissolos Vermelho-Amarelos.

\begin{tabular}{c|c|c}
\hline Segmentos de vertente & Área $\left(\mathbf{k m}^{\mathbf{2}}\right)$ & Ocorrência $\mathbf{( \% )}$ \\
\hline Topo & 20,1 & 15,93 \\
\hline Cumeeira & 34 & 26,94 \\
\hline Ponto sela & 0,2 & 0,16 \\
\hline Planície & 0 & 0,00 \\
\hline Talvegue & 14,7 & 11,65 \\
\hline Depressão fechada & 0 & 0,00 \\
\hline Vertente convexa & 18,2 & 14,42 \\
\hline Vertente em sela & 16,1 & 12,76 \\
\hline Vertente em declive & 0,5 & 0,40 \\
\hline Vertente côncava & 16,9 & 13,39 \\
\hline Inflexão da vertente & 4,6 & 3,65 \\
\hline Não classificado & 0,9 & 0,71 \\
\hline TOTAL & 126,2 & 100,00 \\
\hline
\end{tabular}

Fonte: Elaborado pelos autores.

Por fim, os Gleissolos Háplicos (GX) ocorreram associados às baixas declividades das regiões de talvegue e planície (Figura 9). Em contrapartida, a subordem dos Gleissolos Háplicos na BHBT foi associada ainda às vertentes côncavas (Tabela 9), sinalizando a alta acurácia do algoritmo em identificar solos hidromórficos associados a áreas de várzea, banhados ou de depósitos aluviais.

Figura 9 - Formas da superfície associadas aos Gleissolos Háplicos. 

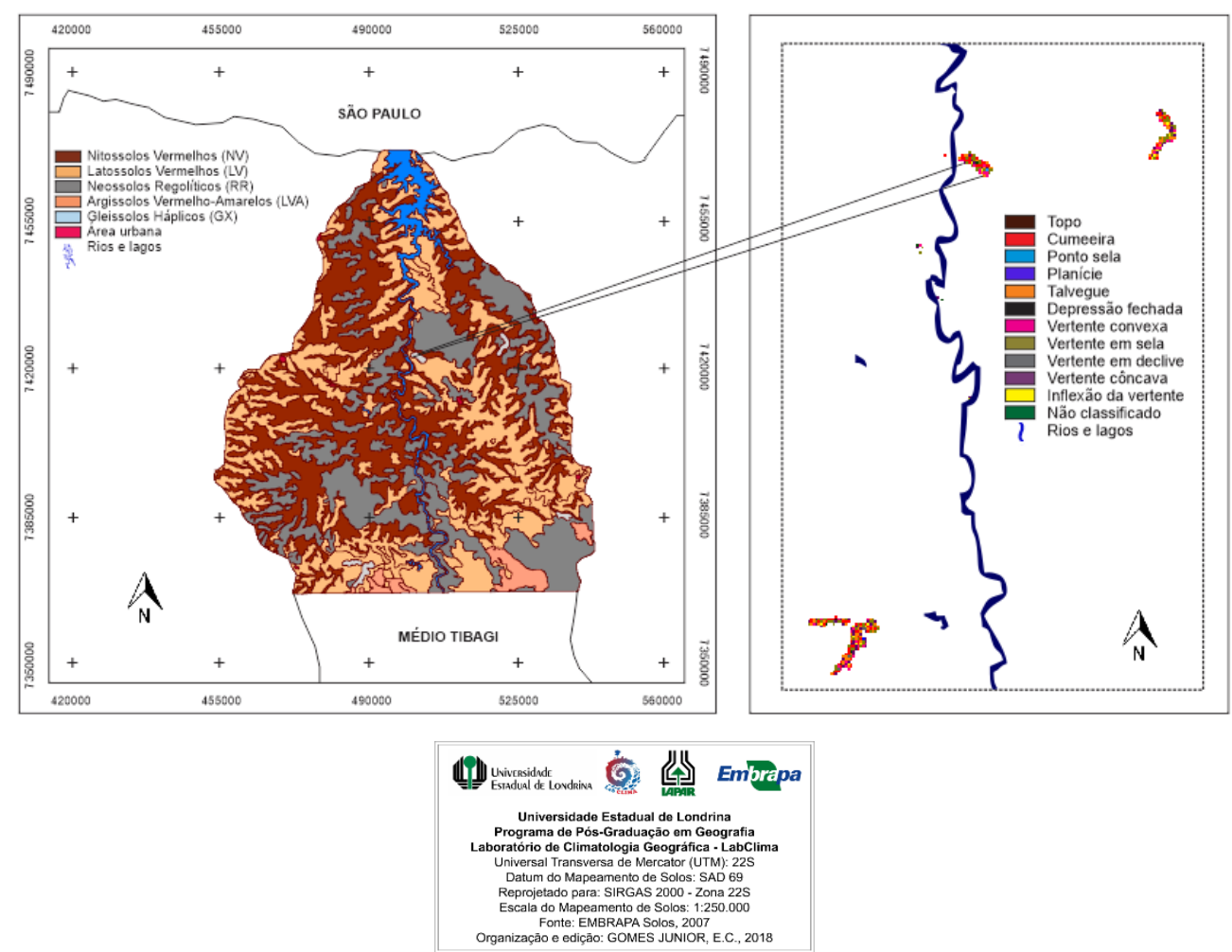

Fonte: Elaborado pelos autores.

Tabela 9. Formas da superfície das vertentes identificadas pelo algoritmo TOPOSHAPE nos Gleissolos Háplicos.

\begin{tabular}{c|c|c}
\hline $\begin{array}{c}\text { Segmentos de } \\
\text { vertente }\end{array}$ & Área $\left.\mathbf{( k m}^{\mathbf{2}}\right)$ & Ocorrência (\%) \\
\hline Topo & 0 & 0,00 \\
\hline Cumeeira & 0,9 & 2,94 \\
\hline Ponto sela & 1,3 & 4,24 \\
\hline Planície & 4,16 & 13,57 \\
\hline Talvegue & 9,9 & 32,29 \\
\hline Depressão fechada & 0 & 0,00 \\
\hline Vertente convexa & 1,7 & 5,54 \\
\hline Vertente em sela & 3,5 & 11,42 \\
\hline Vertente em declive & 0,2 & 0,65 \\
\hline Vertente côncava & 7,1 & 23,16 \\
\hline Inflexão da vertente & 1,5 & 4,89 \\
\hline Não classificado & 0,4 & 1,30 \\
\hline TOTAL & 30,66 & 100,00 \\
\hline \multicolumn{2}{c|}{}
\end{tabular}

Fonte: Elaborado pelos autores. 
Como descrito por Gomes Junior (2017), a associação entre Gleissolos Háplicos e Neossolos Flúvicos em grande parte dos levantamentos pedológicos em nível semidetalhado dificultam a separação destas subordens em nível de mapeamento digital de solos, justamente pela sua proximidade pedogenética e pelo posicionamento preferencial nas áreas mais baixas da vertente.

O critério quali-interpretativo adotado para teste da acurácia do algoritmo, consiste na análise da correlação entre a forma da superfície, que leva em consideração a forma da superfície em si e o fluxo de energia e as classes de solo associadas, utilizando a base e critério propostos pelo Sistema Brasileiro de Classificação de Solos (2013) para classificação das ordens e subordens (Quadro 1). Isso porque as diferentes formas do relevo, intensidade e duração dos processos pedológicos e as características do material de origem determinam o tipo e distribuição do solo nas paisagens, seguindo uma lógica relacionada aos processos (WYSOCKI et al, 2011; MEIRELES et al, 2012).

$\mathrm{O}$ algoritmo classificou tanto feições de topo, como as regiões de cumeeira, quanto pontos no terço inferior da vertente, como talvegue para uma mesma subordem de solo, não criando um padrão de localização para os Nitossolos Vermelhos, dificultando o mapeamento digital de solos para essa subordem.

A disposição dos Latossolos Vermelhos em pontos de cumeeira e topo estão ligados ao fato dessas regiões da vertente serem de declividade entre 0-6\% na BHBT, facilitando a infiltração de água e potencializando a ação pedogenética. Com isso, de maneira geral, os Latossolos Vermelhos são amplamente encontrados em regiões de topo ao terço médio da vertente (LEPSCH, 2011).

As formas da superfície indicadas pelo algoritmo apresentaram concordância nos Neossolos Regolíticos, tendo em vista o predomínio das áreas de vertentes convexas (ponto da vertente de movimentação de massas), as vertentes em declive (áreas de declividade constante) e regiões de cumeeira, que possibilitam a formação de solos rasos.

Assim como nos Latossolos Vermelhos, os Argissolos Vermelho-Amarelos têm como formas da superfície de maior ocorrência as regiões de cumeeira, topo e vertente convexa, respectivamente. Muito influenciado pelo material de origem e pela posição na vertente, os Argissolos estão, em grande parte, associados aos relevos ondulados. Na BHBT, os Argissolos Vermelho-Amarelos estão localizados nas altitudes mais elevadas, superiores a $1.000 \mathrm{~m}$, no curso superior do Rio Tibagi, próximo ao município de Ortigueira, área de transição do Segundo para o Terceiro Planalto Paranaense.

Os Gleissolos Háplicos estão associados na BHBT aos cursos hídricos, ocorrendo nas cotas mais baixas, e em sua totalidade associadas à ordem dos Gleissolos, indicando a eficácia do algoritmo em classificar as áreas de menores altitudes nos fundos de vale e nas planícies aluviais (GOMES JUNIOR, 2017).

De maior ocorrência nos Gleissolos Háplicos da BHBT, as regiões de talvegue e planície indicam a tendência a saturação por água em grande parte do ano. Assim, a predição de ordens de solo hidromórficas, como os Gleissolos, se mostra eficiente visando o mapeamento digital de solos. 
Neste sentido, a modelagem da superfície para aplicação em cartografia de solos, utilizando variáveis morfométricas do relevo, como forma da superfície e comprimento da vertente surge como uma tendência de observação do comportamento pedogeomorfológico, uma vez que a curvatura é responsável pela dissipação ou acumulação de água e sedimentos (FONSECA, 2010). 
Quadro 1 - Quadro síntese contendo a concordância das formas da superfície e solos associados.

\begin{tabular}{|c|c|c|c|c|c|}
\hline Subordem & $\begin{array}{l}\text { Base e critério } \\
\text { (SBCS, 2013) }\end{array}$ & $\begin{array}{c}\text { Forma da } \\
\text { superfície de } \\
\text { maior ocorrência } \\
(\%) \\
\end{array}$ & $\begin{array}{c}\text { Forma da superfície } \\
\text { de } 2^{\mathrm{a}} \text { maior } \\
\text { ocorrência }(\%)\end{array}$ & $\begin{array}{c}\text { Forma da superfície } \\
\text { de } 3^{\mathrm{a}} \text { maior } \\
\text { ocorrência }(\%)\end{array}$ & Concordância \\
\hline $\begin{array}{l}\text { Nitossolos } \\
\text { Vermelhos }\end{array}$ & $\begin{array}{l}\text { Solos profundos, regiões } \\
\text { de topo aplainados, terço } \\
\text { superior a inferior com } \\
\text { relevo plano a ondulado, } \\
\text { textura argilosa ou muito } \\
\text { argilosa }\end{array}$ & Vertente em sela & Talvegue & Cumeeira & $\begin{array}{l}\text { PARCIALMENTE } \\
\text { CONCORDANTE }\end{array}$ \\
\hline $\begin{array}{l}\text { Latossolos } \\
\text { Vermelhos }\end{array}$ & $\begin{array}{c}\text { Solos profundos, regiões } \\
\text { de topos aplainados à } \\
\text { terço inferior com relevo } \\
\text { plano ou suave ondulado } \\
\text { bem drenados } \\
\end{array}$ & Cumeeira & Topo & Vertente convexa & $\begin{array}{l}\text { PARCIALMENTE } \\
\text { CONCORDANTE }\end{array}$ \\
\hline $\begin{array}{l}\text { Neossolos } \\
\text { Regolíticos }\end{array}$ & $\begin{array}{c}\text { Solos rasos, regiões } \\
\text { ombro, terço superior e } \\
\text { inferior com declive } \\
\text { acentuado e contato lítico. }\end{array}$ & Vertente convexa & Vertente em declive & Cumeeira & CONCORDANTE \\
\hline $\begin{array}{c}\text { Argissolos } \\
\text { Vermelho-Amarel } \\
\text { os }\end{array}$ & $\begin{array}{c}\text { Mudança textural abrupta, } \\
\text { regiões de topo a terço } \\
\text { superior e evolução } \\
\text { avançada. }\end{array}$ & Cumeeira & Tоро & Vertente convexa & CONCORDANTE \\
\hline
\end{tabular}




\begin{tabular}{|c|c|c|c|c|c|}
\hline $\begin{array}{c}\text { Gleissolos } \\
\text { Háplicos }\end{array}$ & $\begin{array}{c}\text { Saturação por água, } \\
\text { formado em relevos } \\
\text { planos e material } \\
\text { colúvio-aluvial. }\end{array}$ & Talvegue & Vertente côncava & Planície & CONCORDANTE \\
\hline
\end{tabular}




\section{CONSIDERAÇÕES FINAIS E SUGESTÕES}

As associações observadas entre as formas da superfície e as classes de solo estão em conformidade com a concepção teórica-metodológica (base e critério) de cada subordem pedológica na Bacia Hidrográfica do Baixo Tibagi. Porém, não se observou uma relação pedogenética significativa entre a forma da superfície e os solos em nível de ordem, com exceção para os solos de origem hidromórficas, como os Gleissolos. Por este motivo, o algoritmo matemático computacional TOPOSHAPE mostrou-se eficaz no delineamento das planícies, favorecendo ao reconhecimento prévio das classes de solo nesta região.

A ocorrência de subordens em diferentes formas da superfície, desde áreas de topo a regiões de talvegue, como ocorrido na BHBT com os Nitossolos Vermelhos e Latossolos Vermelhos se torna um ponto passível de adaptação do algoritmo, visto a baixa sensibilidade deste em encontrar padrões específicos quanto às subordens anteriormente citadas. Outra inferência para a dificuldade do algoritmo em localizar formas da superfície em ordens e subordens de solo está na escala do mapeamento utilizado para validação, que é em nível semidetalhado.

Sugere-se que o algoritmo TOPOSHAPE seja aplicado em áreas onde haja ordens de solo de menor representatividade no território brasileiro, como Espodossolos, Vertissolos ou Planossolos, visando observar padrões espaciais entre as formas da superfície e os solos associados, além da validação por mapas pedológicos já publicados em nível detalhado ou ultradetalhado.

\section{REFERÊNCIAS}

BURROUGH, P.A. Principles of Geographical Information Systems for Land Resources Assessement. 1ed. Oxford: Clarendon, 1986. 223p.

COMITE DE BACIAS HIDROGRÁFICAS (CBH). Relatório do diagnóstico da Bacia Hidrográfica do Tibagi. Instituto das Águas do Paraná, 2009.

DAVIS, W.M. The geographical cycle. Geog. Journal, Londres, v.14, p. 481-504, 1899.

EMPRESA BRASILEIRA DE PESQUISA AGROPECUÁRIA. Mapa de solos do Brasil. Brasília: Embrapa Solos, 2006.

EMPRESA BRASILEIRA DE PESQUISA AGROPECUÁRIA. Mapa de solos do Estado do Paraná: legenda atualizada. Rio de Janeiro: Embrapa Florestas, Embrapa Solos e Instituto Agronômico do Paraná, 2008. 74p.

EMPRESA BRASILEIRA DE PESQUISA AGROPECUÁRIA. Sistema Brasileiro de Classificação de Solos. 3 ed. Brasília: Embrapa Solos, 2013. 353p.

FONSECA, I. L. Modelação de formas de relevo para aplicação à cartografia de solos. In: ANAIS DO V CONGRESSO NACIONAL DE GEOMORFOLOGIA. Porto (Portugal), 2010, p.43-55.

GIASSON, E.; SARMENTO, E.C.; WEBER, E.; FLORES, C.A.; HASENACK, H. Decision trees for digital soil mapping on subtropical basaltic steeplands. Scientia Agrícola, São Paulo, v.68, p.167-174, 2011.

GOMES JUNIOR, E.C. Segmentação de vertentes como ferramenta auxiliar no mapeamento digital de solos. 2017. 91p. Dissertação de Mestrado em Engenharia Agrícola - Universidade Estadual de Campinas (UNICAMP).

GONGORA, I. B.; NOBREGA, M.T. Degradação de algumas propriedades de Nitossolos Vermelhos sob diferentes usos da terra no municipio de Maringa/PR. Boletim de Geografia, Maringá, v.20, p.59-68, 2002. 
HERRINGTON, L.; PELLEGRINI, G. An advanced shape of country classifier: extraction of surface features from DEMs. In: PROCEEDINGS OF THE 4TH INTERNATIONAL CONFERENCE ON GIS AND ENVIRONMENTAL

MODELING (GIS/EM4): problems, prospects and research needs. v.1. 2000, Boston, p.4-12.

INSTITUTO BRASILEIRO DE GEOGRAFIA E ESTATÍSTICA - IBGE. Manual Técnico de Pedologia. $2^{\mathrm{a}}$ edição. Rio de Janeiro: IBGE, 2007.

JENNY, H. Factors of soil formation. v.1. New York: McGraw-Hill, 1941. 281 p.

KING. L.C. Canons of landscape evolution. Geological Society of America Bulletin, Nova York, v. 64(7), p. 721-752, 1963.

LAGACHERIE, P.; McBRATNEY, A.B. Spatial soil information systems and spatial soil inference systems: perspectives for digital soil mapping. In: LAGACHERIE, P.; McBRATNEY, A.B.; VOLZ, M. Digital Soil Mapping: an introductory perspective. v.1, Amsterdã: Elsevier, 2007, p. 25-45.

LEINZ, V. Contribuição ao estudo do magmatismo basático Mesozóico da Bacia do Paraná. In: ANAIS DA ACADEMIA BRASILEIRA DE CIÊNCIA, n.40, 1968, Rio de Janeiro, p.168-181.

LEPSCH, I.F. 19 lições de pedologia. $1^{\mathrm{a}}$ ed. São Paulo: Oficina de Textos, 2011. 456 p.

McBRATNEY. A.B.; MENDONÇA-SANTOS. M.L.; MINASNY. B. On digital soil mapping. Amsterdã: Geoderma, v.117, p.3-52, 2003.

MEIRELES, H.T.; MARQUES JUNIOR, J.; CAMPOS, M.C.C.; PEREIRA, G.T. Relações solo-paisagem em topossequência de origem basáltica. Pesq. Agropec. Trop., Goiânia, v. 42, n. 2, p. 129-136, 2012.

MILNE, G. Some suggested units of classification and mapping, particularly for East African Soils. Amsterdã: Soil Resource v. 4, p. 183-198, 1935.

OLIVEIRA, M. T. Estudo de movimentos de massa gravitacionais no município de Belo Horizonte, MG. 2009. 300p. Tese de Doutorado em Engenharia Civil - Universidade Federal de Viçosa (UFV).

PELLEGRINI. G.J. Terrain Shape Classification of Digital Elevation Models using Eigenvectors and Fourier Transforms. 1995. 88p. Dissertação de Mestrado em Geografia - University of New York-Albany.

PENCK, W. Morphological analysis of landforms. London, MacMillan \& Co.,1953. 220p.

PINESE, J. P. P. Síntese Geológica da Bacia do Tibagi. In: MEDRI, M. E. A Bacia do Rio Tibagi. v.1.Londrina: Eduel, 2002. $102 \mathrm{p}$.

RUHE, R.V. Geomorphic Surfaces and the nature of soils. Nova Yor: Soil Sci., v. 82, p.441-445, 1956.

SILVA, C.C. da. Mapeamento digital de classes de solo: aplicação de metodologia na folha de Botucatu (SF-22-Z-B-VI-3) e validação de campo. 2012. 117 p. Dissertação de Mestrado em Agronomia - Instituto Agronômico de Campinas (IAC).

SOUSA, D.M.G.S.; LOBATO, E. Caracterização dos Latossolos Vermelhos. Agência de Informação Embrapa - Bioma Cerrado. v.14, p.6-12, 2008.

STRANG, G. Linear Algebra and its Applications. 1ed. New York: Academic Press, 1976. 342p.

STRONG, D.M. Iterative methods for solving Jacobi's method. Detroit: Mathematical Association of America. v.32, p.5-15, 2007.

TEN CATEN, A.; DALMOLIN, R.S.D.; PEDRON, F.A.; MENDONÇA-SANTOS, M.L. Componentes principais como preditores no mapeamento digital de classes de solos. Santa Maria: Ciência Rural, v.41, n.7, p. 1170-1176, 2011.

WYSOCKI, D.A.; SCHOENEBERGER, P.J.; HIRMAS, D.R.; LAGARRY, H.E. Geomorphology of soil landscapes. In: HUANG. Y. et al. Handbook of Soil Sciences: properties and process. $2^{\circ}$ ed, Boca Raton: 2011. p.29-55.

ZEVENBERGEN. L.W.; THORNE, C.R. Quantitative analysis of land surface topography. Londres: Earth Surface processes and Landforms. v. 12, p. 47-56, 1987. 


\section{COMO CITAR ESTE TRABALHO}

JUNIOR, E.C.G; MARINHO, M. de Andrade \& ELY, D.F. Algoritmo de identificação de formas da superfície aplicado ao reconhecimento pedológico na Bacia Hidrográfica do Baixo Tibagi - Paraná . Revista Tamoios, São Gonçalo, v. 17, n. 2, p. 59-83, 2021. Disponível em: https://doi.org/10.12957/tamoios.2021.48788. Acesso em: DD MM. AAAA. 